\title{
COMMENTARY
}

\section{Cardiac arrest - has the time of MRI come?}

\author{
Damien Galanaud* and Louis Puybasset \\ See related research by Choi et al., http://ccforum.com/content/14/1/R17
}

\begin{abstract}
Three recent articles have shown the potential use of magnetic resonance imaging for the evaluation of comatose survivors of cardiac arrest. While this technique appears promising, significant additional work is required before it can be routinely used in a clinical setting.
\end{abstract}

In the past year, three studies have been published evaluating the use of magnetic resonance imaging (MRI) to determine the prognosis of patients suffering out-ofhospital cardiac arrest, a leading cause of death in developed countries [1-3]. The initial survival of these patients has improved recently thanks to the increased availability of automated defibrillators and induced hypothermia $[4,5]$, leading to an increasing number of patients hospitalized with post-anoxic coma. However, survival rates without major neurological sequelae remain low, and intensive care must be withdrawn in a significant number of patients who will otherwise evolve to a vegetative or minimally conscious state. This decision is currently based on clinical data. Lack of motor response at 24 and 72 hours, absent corneal reflex and pupillary response at 24 hours have been shown to be indicative of poor clinical outcome [6]. This approach, however, has many limitations. While it can reliably predict a poor clinical outcome, prediction of good clinical evolution is still difficult. Among patients with a good clinical outcome, it is impossible to separate those who will have a complete recovery (restitutio ad integrum) from those whose quality of life will be hampered by significant neurological sequelae. Clinical examination can provide variable results and is not compatible with the deep sedation required by some therapeutic protocols, especially hypothermia.

\footnotetext{
*Correspondence: galanaud@gmail.com

Department of Neuroradiology and Neurosurgical Intensive Care Unit Pitié

Salpêtrière Hospital and Université Pierre et Marie curie (Paris VI), Paris 75013, France
}

MRI is now widely available, and, with some precautions, can be performed in patients under mechanical ventilation. Despite the fact that MRI with diffusionweighted imaging (DWI) has been shown to efficiently detect anoxo-ischemic brain injury (especially in stroke), its application for the evaluation of cardiac arrest patients had not been developed until very recently. Three recent papers attempt to address this issue.

In Critical Care, Choi and colleagues [1] have shown in a series of 39 survivors of cardiac arrest that the presence of lesions in both the cortex and basal ganglia on DWI was strongly associated with a poor outcome. Moreover, they could determine cut-off values of the apparent diffusion coefficient (ADC; quantitative data that can be extracted from the DWI sequence) that could predict this outcome with $100 \%$ specificity. Clinical decisions can thus be made based on both reliable quantitative information and images that are useful for explaining the situation to the patient's family. Wijman and colleagues [2] have shown that brain volume with ADC values below certain thresholds correlated with clinical outcome with a better sensitivity than clinical examination. A study by Wu and colleagues [3] basically combined these two approaches and found similar results.

While promising, these three studies share some limitations. They all included a limited number of patients. Due to the rapid time-dependant variations of ADC, MRI can only be performed early ( 2 to 5 days) after the cardiac arrest, during a period when performing this examination is potentially associated with a significant risk, since patients might still require catecholamine. Cut-off values can predict a poor outcome with perfect specificity but less than perfect sensitivity, meaning that, as with clinical examination, while the presence of lesions with a reduced $\mathrm{ADC}$ beyond a defined threshold is strongly suggestive of a poor outcome, a significant number of subjects with a 'good' MRI will also still have a poor outcome. They also share the risk that, if the clinicians were not fully blinded to the result of the MRI, some clinical decisions could have been based on the results of the scan, leading to socalled 'self-fulfilling prophecies'. Finally, all these studies were monocentric. While ADC was initially supposed to be a physical characteristic of the tissue, significant variations in its measurement have been reported, depending 
on the MRI device [7]. These results must thus be confirmed and improved in a multicentric study designed to correct machine dependant variations. If such a study should be performed, introduction of other MRI parameters, such as fractional anisotropy and spectroscopy, might certainly be relevant.

\section{Abbreviations}

$A D C=$ apparent diffusion coefficient; $D W l=$ diffusion- weighted imaging; $\mathrm{MRI}=$ magnetic resonance imaging .

\section{Competing interests}

The authors declare that they have no competing interests.

Published: 26 March 2010

\section{References}

1. Choi SP, Park KN, Park HK, Kim JY, Youn CS, Ahn KJ, Yim HW: Diffusionweighted magnetic resonance imaging for predicting the clinical outcome of comatose survivors after cardiac arrest: a cohort study. Crit Care 2010, 14:R17.

2. Wijman CA, Mlynash M, Caulfield AF, Hsia AW, Eyngorn I, Bammer R, Fischbein $\mathrm{N}$, Albers GW, Moseley M: Prognostic value of brain diffusion-weighted imaging after cardiac arrest. Ann Neurol 2009, 65:394-402
3. Wu O, Sorensen AG, Benner T, Singhal AB, Furie KL, Greer DM: Comatose patients with cardiac arrest: predicting clinical outcome with diffusionweighted MR imaging. Radiology 2009, 252:173-181.

4. Bernard SA, Gray TW, Buist MD, Jones BM, Silvester W, Gutteridge G, Smith K: Treatment of comatose survivors of out-of-hospital cardiac arrest with induced hypothermia. N Engl J Med 2002, 346:557-563.

5. Hallstrom AP, Ornato JP, Weisfeldt M, Travers A, Christenson J, McBurnie MA, Zalenski R, Becker LB, Schron EB, Proschan M; Public Access Defibrillation Tria Investigators: Public-access defibrillation and survival after out-of-hospital cardiac arrest. N Engl J Med 2004, 351:637-646.

6. Booth CM, Boone RH, Tomlinson G, Detsky AS: Is this patient dead, vegetative, or severely neurologically impaired? Assessing outcome for comatose survivors of cardiac arrest. JAMA 2004, 291:870-879.

7. Sasaki M, Yamada K, Watanabe Y, Matsui M, Ida M, Fujiwara S, Shibata E; Acute Stroke Imaging Standardization Group-Japan (ASIST-Japan) Investigators: Variability in absolute apparent diffusion coefficient values across different platforms may be substantial: a multivendor, multi-institutional comparison study. Radiology 2008, 249:624-630.

doi:10.1186/cc8905

Cite this article as: Galanaud D, Puybasset L: Cardiac arrest - has the time of MRI come? Critical Care 2010, 14:135. 